\title{
EEG Power Spectra Changes and Forebrain Ischemia in Rats
}

\author{
Giuseppina Mariucci, Maria Antonietta Stasi, Roberto Taurelli, Paolo Nardò, \\ Michela Tantucci, Licia Pacifici, Paolo Carminati, Maria Vittoria Ambrosini
}

\begin{abstract}
Background: Several animal models of cerebral ischemia have been developed to investigate both pathophysiology and pharmacological treatment. The aim of this study was to verify the prognostic value of EEG power spectra analysis in a two-vessel plus hypotension rat model of transient global ischemia. Methods: Spontaneously hypertensive rats (SHRs) and Wistar Kyoto rats (WKYs) were subjected to 20 min bilateral common carotid artery occlusion plus hypotension by sodium nitroprusside followed by reperfusion for seven days. Sham-operated animals served as controls. The changes after ischemia in EEG power spectra, and their relations with neuronal damage and astrocytic response were investigated. Results: The EEG analysis revealed that in SHRs and WKYs, ischemia produced a dramatic increase in delta activity and a decrease in theta, beta and alpha activities derived from both cortical and hippocampal areas. EEG activity reverted to normal values more quickly in WKYs than in SHRs which did not recover cortical and hippocampal alpha and beta activities even at six days of reperfusion. SHRs presented more severe damage and intense astrocytosis than WKYs in almost all the brain regions analyzed. In SHRs, hippocampal delta activity was positively correlated with the degree of neuronal necrosis and astrocytic activation, whereas theta, alpha and beta activities correlated negatively. No correlations were found in WKYs. Conclusions: These data indicate that the hippocampal bioelectrical activity recorded in SHRs from the beginning of reperfusion could be useful for predicting the ischemic outcome and evaluating the effects of pharmacological interventions.
\end{abstract}

RÉSUMÉ: Changements du spectre électroencéphalographique et ischémie du cerveau antérieur chez le rat. Contexte: Plusieurs modèles animaux ont été développés pour étudier la physiopathologie et le traitement pharmacologique de l'ischémie cérébrale. Le but de cette étude était d'évaluer la valeur pronostique de l'analyse du spectre électroencéphalographique de l'ischémie globale transitoire chez un modèle murin à deux vaisseaux avec hypotension. Méthodes: Des rats spontanément hypertendus (SHRs) et des rats Wistar Kyoto (WKYs) ont été soumis pendant 20 minutes à une occlusion bilatérale de la carotide commune avec hypotension au nitroprusside de sodium, suivie de reperfusion pendant sept jours. Des animaux ayant subi une intervention factice ont servi de témoins. Les changements du spectre électroencéphalographique après ischémie et leurs relations avec le dommage neuronal et la réponse astrocytaire ont été étudiés. Résultats: L'analyse de l'ÉEG a révélé que, chez les SHRs et les WKYs, l'ischémie a provoqué une augmentation dramatique de l'activité delta et une diminution de l'activité thêta, bêta et alpha, même après six jours de reperfusion. Les SHRs présentaient des dommages plus sévères et une astrocytose plus intense que les WKYs dans presque toutes les régions du cerveau analysées. Chez les SHRs, l'activité delta de l'hippocampe était corrélée positivement au degré de nécrose neuronale et à l'activation astrocytaire, alors qu'il existait une corrélation négative avec l'activité thêta, alpha et bêta. On n'a observé aucune corrélation chez les WKYs. Conclusions: Ces données indiquent que l'activité bioélectrique de l'hippocampe enregistrée chez les SHRs à partir du début de la reperfusion pourrait être utile pour prédire les conséquences de l'ischémie et évaluer les effets d'interventions pharmacologiques.

Can. J. Neurol. Sci. 2003; 30: 54-60

Several animal models of cerebral ischemia have been developed to investigate the pathophysiology and evaluate the effectiveness of pharmacologic agents ${ }^{1,2}$ through postmortem biochemical and histological techniques. Methods have rarely, however, been applied to evaluate the in vivo efficacy of possible therapeutical measures or predict the outcome of experimental cerebral ischemia. Magnetic resonance imaging (MRI) is certainly a valid tool to investigate an experimental ischemic brain in vivo but it presents several disadvantages. For instance, animals must be anesthesized, and availability may be limited.

In this study, we evaluated whether electroencephalography could be used to monitor the degree and evolution of ischemic damage in rats. ${ }^{3-6}$ Electroencephalogram (EEG) combined with power spectra analysis can be carried out repeatedly on rats without anaesthesia, is available to many researchers and is employed widely for humans. ${ }^{7-10}$ To verify the prognostic value of this approach we subjected rats to transient bilateral carotid artery occlusion (BCAO) combined with arterial hypotension by sodium

From the Department of Experimental Medicine and Biochemical Sciences, University of Perugia, Perugia (GM, MT, MVA) and SIGMA-TAU Industrie Farmaceutiche Riunite, Pomezia, Roma, (MAS, RT, PN, LP, PC) Italy. ReCEIVEd JANUARY 2, 2002. ACCEPTED IN FinAL FORM OCTOBER 7, 2002. Reprint requests to: Maria Vittoria Ambrosini, Dept of Experimental Medicine and Biochemical Sciences, Division of Cellular and Molecular Biology, University of Perugia, Via del Giochetto, 06122 Perugia, Italy 
nitroprusside. Both early and late postischemic changes in EEG power spectra were evaluated and correlated with the histological damage and astrocytic response at seven days after reperfusion.

\section{MATERIALS AND METHODS}

\section{Animals}

The study was carried out on three-month-old male SHRs $(n=18)$ and WKYs $(n=15)$ weighing approximately $300 \mathrm{~g}$ (Charles River Italia). Before and after the surgical intervention they were kept in a sound-attenuated room at $22 \pm 2^{\circ} \mathrm{C}$, under 12 $\mathrm{h}$ light/dark conditions (7.00 a.m.-7.00 p.m.), with free access to water and food.

\section{Surgery}

Animals were stereotaxically implanted with electrodes under pentobarbital anesthesia $(40 \mathrm{mg} / \mathrm{Kg}$ ip $)$. For EEG recordings, two monopolar stainless steel extradural electrodes $(800 \mu \mathrm{m}$ diameter) were implanted on the right side of the frontal $(3.5 \mathrm{~mm}$ rostrally to the bregma and $2 \mathrm{~mm}$ from the median line) and occipital $(5.0 \mathrm{~mm}$ caudally to the bregma and $3.0 \mathrm{~mm}$ from the median line) skull. One hippocampal electrode (200 $\mu \mathrm{m}$ tefloncoated stainless steel wire, uninsulated for the $0.5 \mathrm{~mm}$ at the tip) was implanted on the left side $3.4 \mathrm{~mm}$ caudally to the bregma, $2.4 \mathrm{~mm}$ from the median line and $3.0 \mathrm{~mm}$ deep from the dura. Reference and ground electrodes were placed in the contralateral nasal and rostral side. After surgery, each rat was placed in a perspex cage $(25 \times 40 \times 40 \mathrm{~cm})$ and allowed to recover for at least eight days before ischemia.

Twenty-four hours before ischemia, anesthesia was induced in rats with $4 \%$ halothane in a $\mathrm{N}_{2} \mathrm{O} / \mathrm{O}_{2}$ (70:30) mixture and maintained during surgery with $0.5-1 \%$ halothane in $\mathrm{N}_{2} \mathrm{O} / \mathrm{O}_{2}$ by a face mask. After a neck incision, both common carotid arteries (CCAs) were dissected from the surrounding tissue and exposed to maximal length. The CCAs were looped and the loops exteriorized through a ventral midline neck incision. Polyethylene rings with 4.0 suture silk thread were placed around the CCAs and care was taken not to compress them. The following day, $2 \mathrm{mg} / 5 \mathrm{ml} / \mathrm{kg}$ of sodium nitroprusside was administered subcutaneously to reduce systemic blood pressure which was monitored by a recorder (U. Basile, Comerio, Italy). Five minutes later, the CCAs were closed by the loops for $20 \mathrm{~min}$ after which blood flow was restored. During ischemia and the recovery, body temperature was maintained at approximately $37^{\circ} \mathrm{C}$ using a heating pad and an overhead lamp and monitored by a rectal thermometer. In sham-operated animals ( $\mathrm{SHR}, \mathrm{n}=3$; WKY, $n=3$ ) both CCAs were dissected and exposed for $20 \mathrm{~min}$, but not occluded. Seven days after ischemia or sham surgery, the animals were deeply anesthetized with pentothal and perfused through the aorta with $100 \mathrm{ml}$ of $0.9 \%$ saline, followed by 500 $\mathrm{ml}$ of $10 \%$ formaline in $0.1 \mathrm{M}$ posphate buffer $\mathrm{pH} 7.4$ (PB). The brains were removed and post-fixed in the same fixative for at least $48 \mathrm{~h}$. The entire brain was embedded in paraffin, and serial coronal sections $(7 \mu \mathrm{m})$ were cut throughout the brain along the rostrocaudal axis and processed for routine histology and immunohistochemistry analysis.

\section{EEG recording and power spectra analysis}

EEG activity was recorded by a Vega 24 polygraph (ESAOTE, Roma, Italy) on paper and digitalized on-line using an IBM-XT compatible personal computer equipped with an A/D converter (A/D conversion rate $64 \mathrm{~Hz}$ ). Poligraph bandpass filters were set to cut-off at frequencies below 0.25 and above 30 $\mathrm{Hz}$ at $10 \mathrm{~dB}$ /octave. A $50 \mathrm{~Hz}-30 \mathrm{~dB} /$ octave notch filter was also employed to further reduce power line noise. Frontal, occipital and hippocampal EEGs were simultaneously recorded.

During EEG recording, rats were allowed to move freely in their cages by means of a rotating electrical connector. EEG recordings, lasting $1 \mathrm{~h}$ each, were perfomed the day before ischemia (day 1) and $48 \mathrm{~h}$ and six days after ischemia. The EEG was also monitored continually during the ischemic period and for $5 \mathrm{~h}$ after reperfusion. Throughout the recording sessions, the animals' behavior, posture and motor activity levels were continuously monitored.

For power spectra analysis, the digitalized EEGs were visually coded and sequentially scored in $2 \mathrm{sec}$ epochs. Active and quiet wakefulness, synchronized sleep and paradoxical sleep were identified on the basis of behavioral and EEG criteria. EEG artifacts were discarded. Only the EEG segments pertaining to quiet wakefulness (characterized by a lack of activity, a sphinxlike posture with open eyes fixed on a particular familiar object and, from time to time, scanning the interior of the experimental chamber) were submitted to power spectra analysis. Power spectra analysis was performed in consecutive $2 \mathrm{sec}$ epochs in the frequency range of $1-22 \mathrm{~Hz}$, with a resolution of $1 \mathrm{~Hz}$. For each animal we calculated a spectrum which was the average of the spectral values of 30 epochs; the average spectrum was expressed as absolute $\left(\mu \mathrm{V}^{2} / \mathrm{Hz}\right)$ and relative power density units (\% of total spectral power). The absolute and the relative power of the delta (1-4 Hz), theta (4-8 Hz), alpha (8-13 HZ) and beta (13-22 Hz) bands were calculated. However, results of the power spectral analysis were presented in terms of relative power density to reduce individual variability.

\section{Histopathology}

Sections were stained with cresyl violet to evaluate neuronal damage or necrosis in the neocortex, striatum, thalamus, hypothalamus and $\mathrm{CA} 1, \mathrm{CA} 2$ and $\mathrm{CA} 3$ regions of the hippocampus. Necrotic cells were considered only if they had a shrunken cytoplasm and condensed nucleus. The severity of neuronal damage was graded using a semiquantitative scale of 0 4 according to our previous report 6 : $0=$ no cell necrosis, $1=$ few single-cell and/or cell group necrosis, 2 = areas of larger cell group necrosis, $3=$ mostly necrotic cells, $4=$ complete cell necrosis.

Immunohistochemistry was carried out to evaluate astrocytic expression of glial fibrillary acidic protein (GFAP) and vimentin (Vim). Adjacent sections were sequentially incubated with: i) $10 \%$ normal goat serum in Tris buffered saline containing $0.03 \%$ Triton X100 (TBST) for $30 \mathrm{~min}$, ii) polyclonal anti-GFAP antibody (1:200 in TBST, DAKO, Glostrup, Denmark) for 30 min or anti-vimentin antibody overnight (1:100 in TBST, Sigma, St. Louis, MO), iii) biotinylated secondary antibody (1:40 for GFAP, 1:100 for Vim, Vector Labs, Burlingame, CA) for $30 \mathrm{~min}$ and iiii) the avidin-biotin peroxidase complex (Vectastain ABC Kit, Vector Labs.) for $45 \mathrm{~min}$. The reaction product was visualized by incubation with $\mathrm{H}_{2} \mathrm{O}_{2}$ and 3-3'-diaminobenzidine (DAB, Sigma). Representative control sections were processed as described above except that the primary antibody was 
replaced by TBST. GFAP and vimentin immunoreactivity (GFAP-IR and Vim-IR respectively) were graded using a semiquantitative $0-3$ scale: $0=$ no staining, $1=$ weak, $2=$ moderate, 3 = strong. The histological examination was carried out by an investigator unaware of the strain of the animal and treatment given.

\section{Statistics}

The Mann-Whitney U-test was used to compare score differences in histopathology, GFAP-IR and Vim-IR between groups. Repeated measure analyses of variance (ANOVA) with one repeated factor (EEG recordings) and one grouping factor (SHR and WKY ischemic rats) were performed on the relative spectral values of delta, theta, alpha and beta bands for each cerebral region. Correlative analysis between spectral EEG data and histopathology, GFAP-IR and Vim-IR was based on nonparametric Spearman's rank-order method.

\section{RESULTS}

\section{Behavioral and electrophysiological data}

In the ischemic SHR group, one rat died after 7 min of carotid clamping and three within 24 and $48 \mathrm{~h}$ of reperfusion. No death occurred in either ischemic WKY rats or sham-operated controls.

Before nitroprusside treatment, the mean blood pressure of WKYs was about $110-120 \mathrm{mmHg}$ while that of SHRs was $180 \mathrm{mmHg}$. Five minutes after sodium nitroprusside injection, the mean blood pressure was reduced to $72.5 \pm 2.3 \mathrm{mmHg}$ in WKYs and $52.6 \pm 2.7 \mathrm{mmHg}$ in SHRs $(\mathrm{p}<0.0001)$. The blood pressure values reverted to basal values in WKYs within 1-1.5 h whereas recovery in SHRs was slower (data not shown).

No rat experienced seizures during or after ischemia. In SHRs, global ischemia was identified by an almost isoelectric EEG, depression of spontaneous motor activity, absence of a response to external stimuli, and shallow and rapid respiration. Immediately after reperfusion, SHRs showed moderate to severe neurological signs such as drowsiness, no spontaneous movement, but occasional movements when handled, circling and/or hyperactivity. Their behavior tended to normalize by the fifth hour after reperfusion. On the contrary, immediately after reperfusion, some WKYs were asymptomatic whereas others showed behavioral changes which were fairly similar, but to a lesser degree, to those observed in SHRs.

The almost isoelectric EEG, indicative of global ischemia, was recorded within 2 min of BCAO and persisted throughout the $20 \mathrm{~min}$ ischemic period in $75 \%$ of the SHRs. In the remaining $25 \%$ of the SHRs and in all the WKYs the EEG signal amplitude was reduced by about $70-80 \%$ compared to baseline. There was no change in the EEG of SHR or WKY sham-controls (data not shown).

After reperfusion, in both ischemic groups cerebral bioelectrical activity varied significantly from baseline. The relative EEG power spectra values of individual bands relative to the frontal cortex of WKYs and SHRs are shown in Figure 1. Repeated measure ANOVA for the delta band indicated significant effects for strain $\left(\mathrm{F}_{1,21}=15.6, \mathrm{p}<0.001\right)$ and time $\left(\mathrm{F}_{6,126}=17.3, \mathrm{p}<0.001\right)$ and no interaction effect. Delta activity increased during ischemia, but it reverted to normal values in WKYs faster than in SHRs. Ischemia induced a decrease in theta activity. For this band, significant differences were observed between groups $\left(\mathrm{F}_{1,21}=7.1, \mathrm{p}<0.01\right)$ and recording times $\left(\mathrm{F}_{6,126}\right.$ $=14.2, \mathrm{p}<0.001)$. Ischemia also induced a reduction in alpha and beta activities. Repeated measure ANOVA revealed a significant strain effect $\left(\mathrm{F}_{1,21}=16\right.$ and $\mathrm{F}_{1,21}=24.8, \mathrm{p}<0.001$, for the alpha and beta bands respectively) and a significant change over time $\left(\mathrm{F}_{6,126}=12.2\right.$ and $\mathrm{F}_{6,126}=9.8, \mathrm{p}<0.001$ for the alpha and beta bands respectively). Further strain $\mathrm{x}$ time interaction was only significant for the beta band $\left(\mathrm{F}_{6,126}=4.9, \mathrm{p}<0.001\right)$. WKY rats recovered alpha and beta activities at $1 \mathrm{~h}$ of reperfusion unlike SHRs which had a delayed alpha band recovery $(5 \mathrm{~h})$ and values for beta activity that were always lower than baseline.

Figure 2 gives the EEG activity in the occipital cortex. Repeated measure ANOVA indicated a significant strain effect for delta, alpha and beta bands $\left(\mathrm{F}_{1,21}=6.2, \mathrm{p}<0.05, \mathrm{~F}_{1,21}=8.9\right.$, $\mathrm{p}<0.01, \mathrm{~F}_{1,21}=9.9, \mathrm{p}<0.01$, respectively). Furthermore, it gave a significant time effect for all bands $\left(\mathrm{F}_{6,126}=14.4\right.$ for delta; $\mathrm{F}_{6,126}$ $=10.3$ for theta $; \mathrm{F}_{6,126}=13.7$ for alpha; $\mathrm{F}_{6,126}=10.4$ for beta, $\mathrm{p}<0.001)$ and a significant strain $\mathrm{x}$ time interaction for alpha $\left(\mathrm{F}_{6,126}=2.3, \mathrm{p}<0.05\right)$ and beta $\left(\mathrm{F}_{6,126}=4.3, \mathrm{p}<0.001\right)$ activities. WKYs recovered total occipital EEG activity within $5 \mathrm{~h}$ of reperfusion unlike SHRs which reverted to basal delta and theta activities but not alpha and beta ones.

Hippocampal EEG activity (Figure 3) showed significant differences between strains $\left(\mathrm{F}_{1,21}=8.9\right.$ for delta, $\mathrm{F}_{1,21}=7.6$ for theta, $\mathrm{F}_{1,21}=7.9$ for alpha, $\mathrm{F}_{1,21}=7.2$ for beta, $\mathrm{p}<0.01$ ) and over time for all bands $\left(F_{6,126}=11.8\right.$ for delta, $F_{6,126}=9.8$ for theta, $\mathrm{F}_{6,126}=13.6$ for alpha, $\mathrm{F}_{6,126}=4.5$ for beta, $\left.\mathrm{p}<0.001\right)$. There was a significant strain $\mathrm{x}$ time interaction for alpha $\left(\mathrm{F}_{6,126}=4\right.$, $\mathrm{p}<0.001)$ and beta $\left(\mathrm{F}_{6,126}=2.4, \mathrm{p}<0.05\right)$ activities. As in the occipital cortex, the WKY group recovered normal EEG activity in the hippocampal region within $5 \mathrm{~h}$ after ischemia whereas SHRs tended toward baseline in the delta and theta bands within the first hours but did not show any such tendency regarding alpha and beta bands even at six days of reperfusion.

\section{Correlation between histological and electrophysiological data}

All ischemic rats had ventricular dilatation but it was less in WKYs than SHRs.

In many cerebral areas, SHRs had an average histopathological score higher than that of WKYs (Figure 4A). SHRs had an infarction in the parietal cortex that in several animals extended to the frontal and temporal cortex and striatum. About $35 \%$ of the SHRs had complete cell necrosis in the hippocampal areas, whereas the others had lesions of variable degrees. WKYs had prominent lesions in the parietal cortex and striatum, whereas slight changes were detected in the other regions. No histological damage was found in any of the shamoperated controls.

Correlative analyses between histopathology and frontal or occipital EEG activity revealed sporadic and very few correlations, and these were completely lacking at six days in both strains (data not shown). Numerous correlations between hippocampal EEG activity and the histopathology of hippocampal subfields were found in SHRs (Table 1). The delta activity at the different recording times was positively correlated with the hippocampal damage found after seven days of reperfusion. There were negative and significant correlations between theta and beta activities and hippocampal damage at all 
Table 1: Nonparametric correlation coefficients between histopathological score and relative power spectra of delta, theta, alpha and beta bands in hippocampus.

\begin{tabular}{|c|c|c|c|c|c|c|c|c|c|c|c|}
\hline \multirow[b]{2}{*}{ REGION } & \multicolumn{2}{|c|}{$15 \mathrm{~min}$} & \multicolumn{2}{|c|}{$1 \mathrm{~h}$} & \multicolumn{2}{|c|}{$5 \mathrm{~h}$} & \multicolumn{2}{|c|}{$48 \mathrm{~h}$} & \multicolumn{2}{|c|}{6 days } & \multirow[b]{2}{*}{ EEG ACTIVITY } \\
\hline & SHR & WKY & SHR & WKY & SHR & WKY & SHR & WKY & SHR & WKY & \\
\hline CA2 & $0.64^{\mathrm{a}}$ & -0.31 & $0.88^{\mathrm{b}}$ & 0.41 & $0.84^{\mathrm{b}}$ & 0.20 & $0.74^{\mathrm{a}}$ & 0.17 & $0.81^{\mathrm{b}}$ & -0.26 & \\
\hline CA3 & $0.65^{\mathrm{a}}$ & -0.25 & $0.87^{\mathrm{b}}$ & 0.48 & $0.66^{\mathrm{a}}$ & 0.21 & $0.83^{b}$ & 0.17 & $0.83^{\mathrm{b}}$ & -0.32 & \\
\hline CA2 & $-0.75^{a}$ & 0.31 & $-0.91^{c}$ & -0.36 & $-0.74^{\mathrm{a}}$ & -0.26 & -0.45 & -0.26 & $-0.73^{a}$ & 0.01 & \\
\hline CA3 & $-0.72^{\mathrm{a}}$ & 0.27 & $-0.87^{b}$ & -0.42 & -0.50 & -0.23 & $-0.66^{\mathrm{a}}$ & -0.26 & $-0.79^{b}$ & 0.06 & \\
\hline CA1 & -0.58 & 0.21 & $-0.89^{c}$ & -0.15 & $-0.93^{c}$ & 0.06 & $-0.79^{b}$ & 0.11 & -0.51 & 0.07 & ALPHA (8-13 Hz) \\
\hline CA2 & -0.58 & 0.41 & $-0.89^{c}$ & 0.10 & $-0.93^{c}$ & 0.10 & $-0.79^{b}$ & 0.26 & -0.51 & 0.01 & \\
\hline CA3 & -0.60 & 0.34 & $-0.78^{b}$ & 0.05 & $-0.91^{c}$ & 0.10 & $-0.76^{\mathrm{a}}$ & 0.26 & -0.55 & 0.03 & \\
\hline
\end{tabular}

CA1, CA2 and CA3: hippocampal subfields.

EEG session: $15 \mathrm{~min}, 1 \mathrm{~h}, 5 \mathrm{~h}, 48 \mathrm{~h}$ and 6 days after ischemia

${ }^{\mathrm{a}} \mathrm{p}<0.05,{ }^{\mathrm{b}} \mathrm{p}<0.01,{ }^{\mathrm{c}} \mathrm{p}<0.005$

Table 2: Nonparametric correlation coefficients between GFAP immonoreactivity score and relative power spectra of delta, theta, alpha and beta bands in hippocampus.

\begin{tabular}{|c|c|c|c|c|c|c|c|c|c|c|c|}
\hline \multirow[b]{2}{*}{ REGION } & \multicolumn{2}{|c|}{$15 \mathrm{~min}$} & \multicolumn{2}{|c|}{$1 \mathrm{~h}$} & \multicolumn{2}{|c|}{$5 \mathrm{~h}$} & \multicolumn{2}{|c|}{$48 \mathrm{~h}$} & \multicolumn{2}{|c|}{6 days } & \multirow[b]{2}{*}{ EEG ACTIVITY } \\
\hline & SHR & WKY & SHR & WKY & SHR & WKY & SHR & WKY & SHR & WKY & \\
\hline CA2 & 0.56 & 0.38 & $0.95^{\mathrm{c}}$ & 0.22 & $0.69^{a}$ & 0.34 & $0.73^{\mathrm{a}}$ & -0.41 & $0.83^{\mathrm{b}}$ & 0.23 & \\
\hline CA3 & 0.59 & 0.34 & $0.95^{c}$ & 0.24 & $0.68^{a}$ & 0.13 & $0.75^{\mathrm{a}}$ & -0.20 & $0.84^{\mathrm{b}}$ & 0.01 & \\
\hline $\mathrm{CA} 2$ & $-0.66 \mathrm{a}$ & -0.37 & $-0.95^{c}$ & -0.16 & -0.57 & -0.25 & -0.53 & 0.33 & $-0.81^{b}$ & -0.33 & \\
\hline CA3 & $-0.69^{a}$ & -0.31 & $-0.95^{c}$ & -0.23 & -0.56 & -0.02 & -0.55 & 0.10 & $-0.81^{b}$ & -0.08 & \\
\hline CA1 & -0.45 & -0.21 & $-0.90^{c}$ & 0.16 & $-0.79^{a}$ & -0.54 & $-0.67^{a}$ & 0.01 & -0.57 & 0.13 & ALPHA (8-13 Hz) \\
\hline CA2 & -0.59 & -0.21 & $-0.92^{c}$ & 0.16 & $-0.83^{b}$ & -0.54 & $-0.75^{a}$ & 0.01 & -0.61 & 0.13 & \\
\hline CA3 & -0.61 & -0.27 & $-0.91^{c}$ & 0.13 & $-0.84^{b}$ & -0.36 & $-0.76^{a}$ & -0.16 & -0.61 & -0.05 & \\
\hline
\end{tabular}

CA1, CA2 and CA3: hippocampal subfields.

EEG session: $15 \mathrm{~min}, 1 \mathrm{~h}, 5 \mathrm{~h}, 48 \mathrm{~h}$ and 6 days after ischemia.

${ }^{\mathrm{a}} \mathrm{p}<0.05,{ }^{\mathrm{b}} \mathrm{p}<0.01,{ }^{\mathrm{c}} \mathrm{p}<0.005$. 


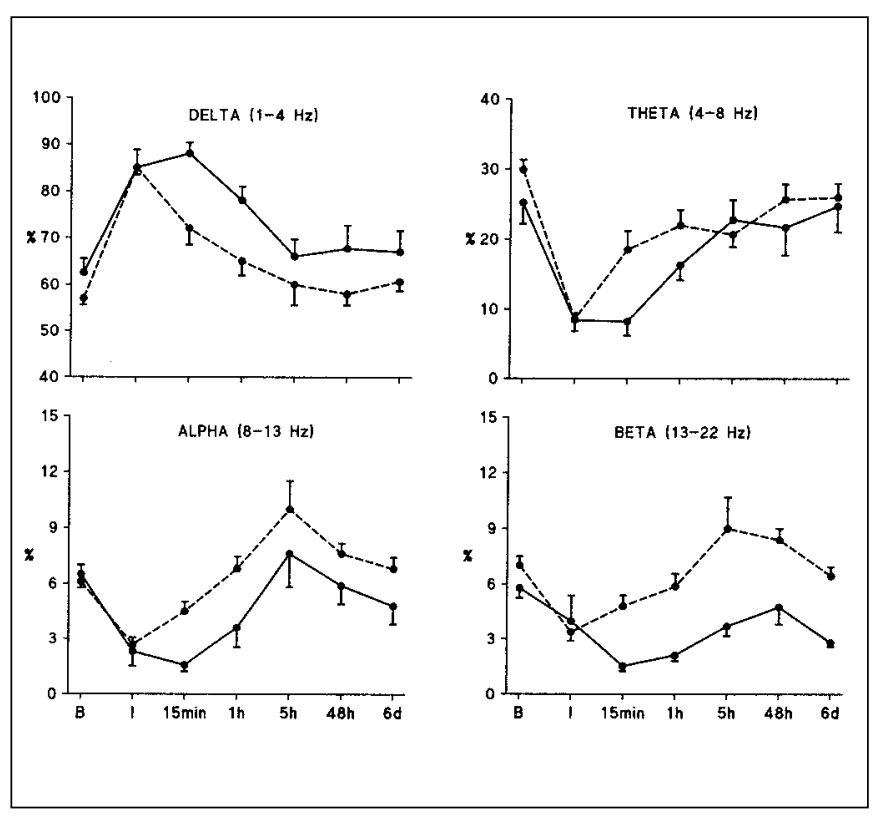

Figure 1: Percentage of spectral power of delta, theta, alpha and beta bands recorded in the frontal cortex of SHR (solid line) and WKY (dashed line) rats before, during and at different times after ischemia B, baseline; I, ischemia; $15 \mathrm{~min}, 1 \mathrm{~h}, 5 \mathrm{~h}, 48 \mathrm{~h}, 6 \mathrm{~d}$, post-ischemic times.

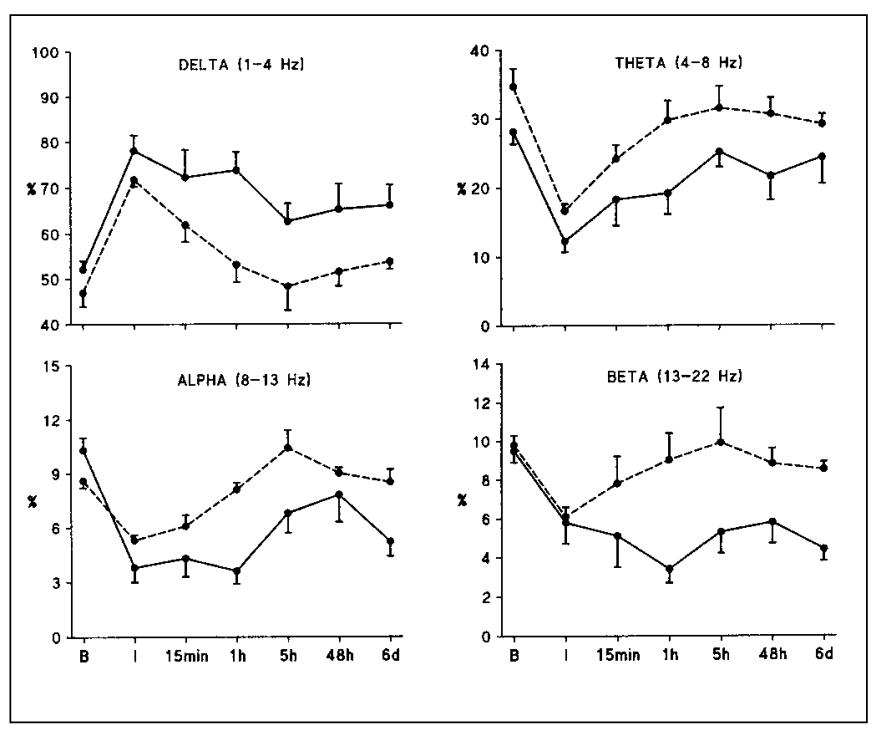

Figure 3: Percentage of spectral power of delta, theta, alpha and beta bands recorded in the hippocampus of SHR (solid line) and WKY (dashed line) rats before, during and at different times after ischemia B, baseline; I, ischemia; $15 \mathrm{~min}, 1 \mathrm{~h}, 5 \mathrm{~h}, 48 \mathrm{~h}, 6 \mathrm{~d}$, post-ischemic times.

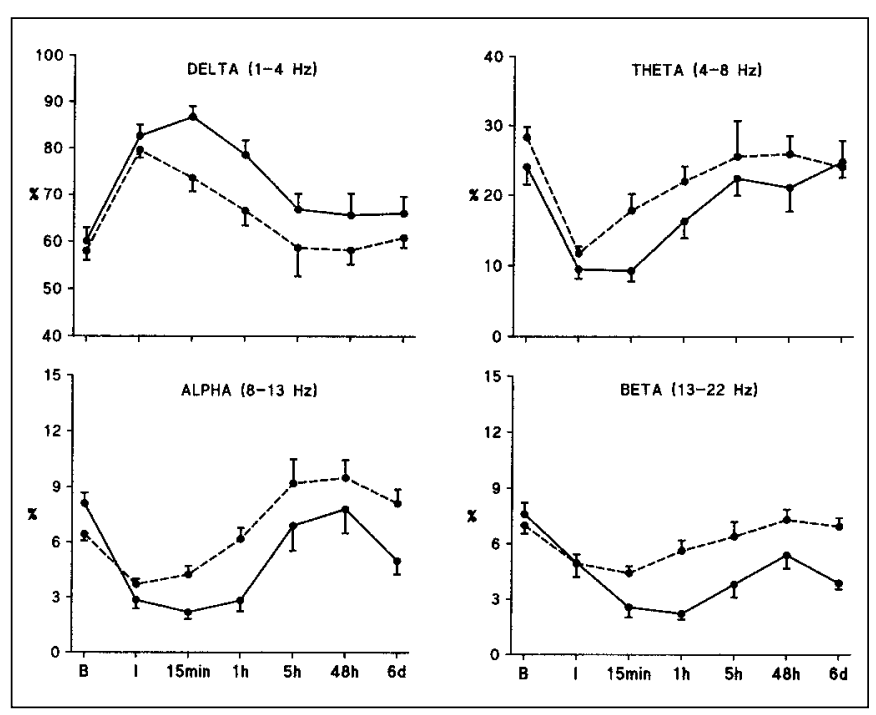

Figure 2: Percentage of spectral power of delta, theta, alpha and beta bands recorded in the occipital cortex of SHR (solid line) and WKY (dashed line) rats before, during and at different times after ischemia B, baseline; I, ischemia; $15 \mathrm{~min}, 1 \mathrm{~h}, 5 \mathrm{~h}, 48 \mathrm{~h}, 6 \mathrm{~d}$, post-ischemic times.

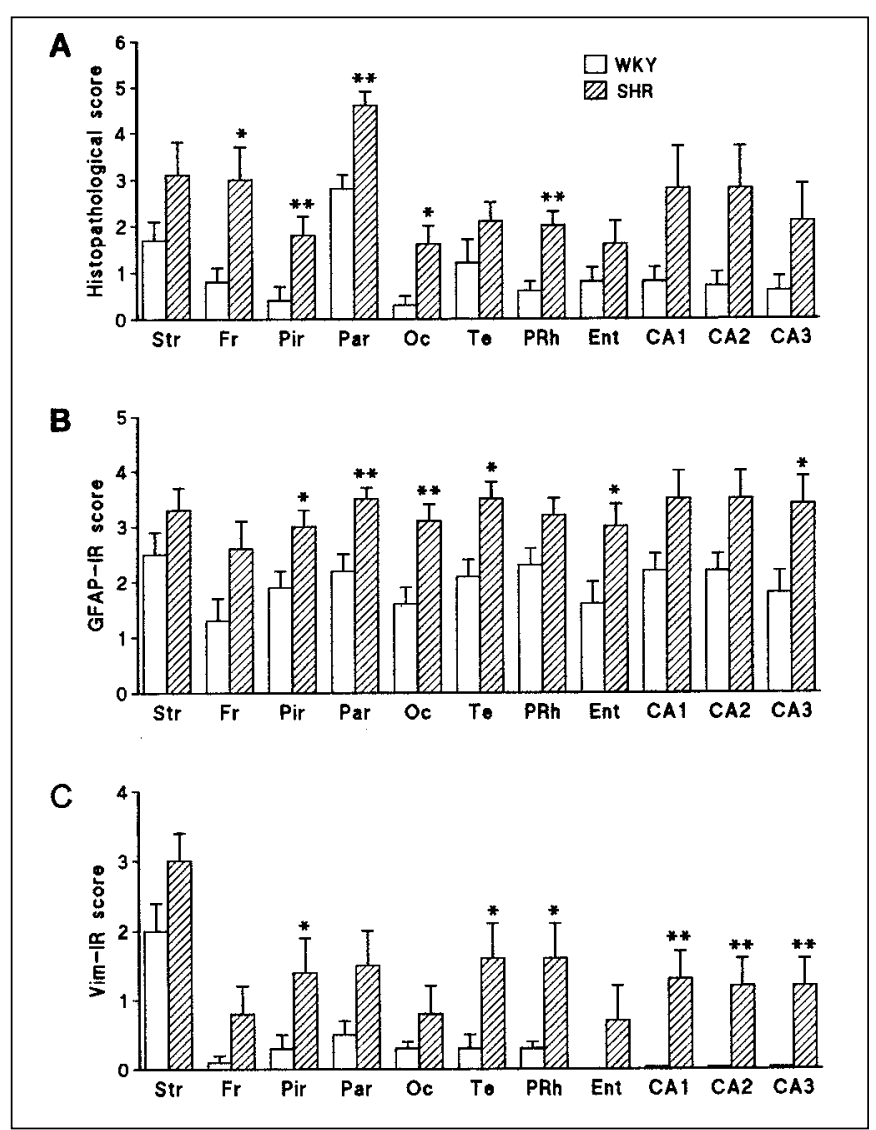

Figure 4: Data represent the mean \pm SEM of total scores (right + left hemisphere) of histopathological damage (A) and immunoreactivity for GFAP (B) and vimentin (Vim) (C) in ischemic SHR and WKY rats. Str, striatum; Fr, frontal cortex; Pir, piriform cortex; Par, parietal cortex; Oc, occipital cortex; Te, temporal cortex; PRh, perirhinal cortex; Ent, entorinal cortex; CA1, CA2 and CA3 hippocampal regions. SHR vs $W K Y: * p<0.05$, ** $p<0.005$ (U-test). 
Table 3: Nonparametric correlation coefficients between Vimentin immunoreactivity score and relative power spectra of delta, theta, alpha and beta bands in hippocampus of SHRs.

\begin{tabular}{|c|c|c|c|c|c|c|}
\hline \multicolumn{2}{|c|}{ REGION 15 min } & \multirow{2}{*}{$\begin{array}{l}1 \mathrm{~h} \\
0.76^{\mathrm{a}}\end{array}$} & \multirow{2}{*}{$\begin{array}{l}5 \mathbf{h} \\
0.72^{\mathrm{a}}\end{array}$} & \multirow{2}{*}{$\begin{array}{l}48 \mathrm{~h} \\
0.75^{\mathrm{a}}\end{array}$} & \multirow{2}{*}{$\begin{array}{l}6 \text { days } \\
0.82^{b}\end{array}$} & \multirow{2}{*}{$\begin{array}{l}\text { EEG } \\
\text { ACTIVITY } \\
\text { DELTA }\end{array}$} \\
\hline CA1 & 0.57 & & & & & \\
\hline CA2 & $0.67^{\mathrm{a}}$ & $0.87^{b}$ & $0.81^{\mathrm{a}}$ & $0.85^{\mathrm{b}}$ & $0.87^{\mathrm{b}}$ & \multirow[t]{2}{*}{$(1-4 \mathrm{~Hz})$} \\
\hline CA3 & $0.67^{\mathrm{a}}$ & $0.87^{b}$ & $0.81^{\mathrm{a}}$ & $0.85^{b}$ & $0.87^{\mathrm{b}}$ & \\
\hline CA1 & -0.61 & $-0.79^{a}$ & -0.54 & -0.53 & $-0.74^{\mathrm{a}}$ & \multirow{3}{*}{$\begin{array}{c}\text { THETA } \\
\text { (4-8 Hz) }\end{array}$} \\
\hline $\mathrm{CA} 2$ & $-0.73^{a}$ & $-0.91^{\mathrm{c}}$ & $-0.67^{\mathrm{a}}$ & -0.60 & $-0.79^{a}$ & \\
\hline CA3 & $-0.73^{a}$ & $-0.91^{\mathrm{c}}$ & $-0.67^{\mathrm{a}}$ & -0.60 & $-0.79^{a}$ & \\
\hline CA1 & -0.57 & $-0.77^{\mathrm{a}}$ & $-0.87^{b}$ & $-0.81^{\mathrm{a}}$ & -0.53 & \multirow{3}{*}{$\begin{array}{l}\text { ALFA } \\
(8-13 \text { Hz })\end{array}$} \\
\hline $\mathrm{CA} 2$ & $-0.67^{a}$ & $-0.85^{b}$ & $-0.89^{c}$ & $-0.89^{c}$ & $-0.66^{a}$ & \\
\hline CA3 & $-0.67^{\mathrm{a}}$ & $-0.58^{b}$ & $-0.89^{c}$ & $-0.89^{c}$ & $-0.66^{\mathrm{a}}$ & \\
\hline CA1 & -0.61 & $-0.74^{\mathrm{a}}$ & $-0.64^{\mathrm{a}}$ & $-0.81^{b}$ & $-0.79^{a}$ & \multirow{3}{*}{$\begin{array}{l}\text { BETA } \\
(13-22 \mathrm{~Hz})\end{array}$} \\
\hline $\mathrm{CA} 2$ & $-0.70^{a}$ & $-0.75^{a}$ & $-0.72^{a}$ & $-0.93^{c}$ & $-0.84^{b}$ & \\
\hline CA3 & $-0.70^{a}$ & $-0.75^{a}$ & $-0.72^{a}$ & $-0.93^{c}$ & $-0.84^{b}$ & \\
\hline
\end{tabular}

CA1, CA2 and CA3 hippocampal subfields

EEG session: $15 \mathrm{~min}, 1 \mathrm{~h}, 5 \mathrm{~h}, 48 \mathrm{~h}$ and 6 days after ischemia. ${ }^{\mathrm{a}} \mathrm{p}<0.05,{ }^{\mathrm{b}} \mathrm{p}<0.01,{ }^{\mathrm{c}} \mathrm{p}<0.005$.

times while the alpha band attained a significant negative correlation at 1, 5 and 48 hours only. Unlike SHRs, only two correlations were found in WKYs: the histopathological score for the CA1 subfield was positively correlated with delta and negatively with the theta band at $1 \mathrm{~h}$.

In SHRs, GFAP expression was significantly higher than that of WKYs mainly in cortical and hippocampal areas (Figure 4B). GFAP-IR was generally absent within necrotic regions but intensely stained astrocytes were found in the surrounding zones. A weak GFAP-IR (Grade 0-1) was found in sham-operated rats. Hippocampal GFAP-IR correlated positively with the delta band and negatively with other bands in SHRs. No correlations were present in WKYs (Table 2).

Moderate to strong Vim-IR was found in the striatum of both strains (Figure 4C). SHRs also displayed Vim-positive cells in the hippocampus and some cortical areas, particularly at the level of the perinecrotic zones. In the sham-operated animals no VimIR was detected. The correlative analysis demonstrated that hippocampal Vim-IR was positively correlated with the delta band and negatively with the other ones in SHRs (Table 3).

\section{DiscuSSION}

From the present study it is apparent that bilateral carotid ligation combined with systemic hypotension caused cerebral damage and behavioral and EEG changes more severe in spontaneously hypertensive rats than in Wistar Kyoto ones.

Apart from the differences in EEG activity detected during bilateral carotid artery occlusion, EEG power spectra analysis demonstrated that after reperfusion the bioelectrical cerebral activity was restored more quickly in the WKYs than in the SHRs, where EEG alterations were still present by the sixth day.

As a consequence of the different degrees of ischemia, SHRs showed more pronounced cerebral lesions and reactive astrocytosis than WKYs. In both groups, the histological data were consistent with the results of the immunohistochemical analysis performed to evaluate astrocytic activation. SHRs showed more intense astrocytosis than WKYs. A similar pattern of GFAP-IR and Vim-IR distribution was detected in the SHRs whereas in the WKYs GFAP-IR was widespread and Vimpositive astrocytes were only present in the striatum, the most injured region in both strains.

Although their role in gliosis is still not completely clear, GFAP and Vim are considered markers for assessing astrocyte response to injury. Upregulation of GFAP expression is detected in astrocytes following different pathological stimuli ${ }^{11-15}$ and Vim-positive astrocytes, not normally observed in the adult brain, may reappear after severe injury. ${ }^{11,13-18}$ For this reason, astrocytes expressing exclusively GFAP are considered hypertrophic whereas astrocytes co-expressing GFAP and Vim are considered to be proliferating cells. ${ }^{17}$ After ischemia, an increase in GFAP can be expressed both in proximity to and distant from the infarct, whereas Vim-positive astrocytes are only detected near the lesions. ${ }^{11,17}$ Also under our conditions, the different types of astrocytic activation were related to the degree of tissue damage and Vim-positive astrocytes surrounding the infarcted necrotic areas seemed to indicate that repair was in progress.

The correlative study between EEG and the histopathological data concerning WKYs showed that EEG analysis was unable to predict histological outcome, as we observed in a gerbil model of global ischemia. ${ }^{6}$ The lack of correlations in the WKY group can partly be explained by the slight cerebral injury found at seven days after ischemia. Therefore, it is likely that the early EEG changes were largely an expression of transient cerebral alterations that did not induce permanent lesions. In SHRs the cerebral lesions and reactive astrocytosis found at seven days were greater than those detected in WKYs and neuron function, evaluated by EEG, had not been restored even at six days of reperfusion. It is likely that changes in bioelectric activity were the expression of parenchymal damage that evolved into widespread and permanent lesions. However, no significant correlations were found between EEG data and histopathological scores with the exception of the hippocampal areas. The lack of correlations between EEG activity derived from frontal and occipital extradural electrodes and histopathology might be due to the lack of specific spatial relations between the EEG activity and the individual regions considered. On the contrary, the deep hippocampal electrode recorded from severely damaged hippocampus.

On the whole, our data are in keeping with previous studies which demonstrate that SHRs are more sensitive to ischemia than normotensive strains. ${ }^{19-23}$ It has been suggested that the high vulnerability of SHRs may depend on their hypertensive status and related consequences, i.e. hemodynamic alterations ${ }^{19}$ and morphological vascular changes. ${ }^{24}$ Other recent studies have pointed out that genetic factors may also be involved. ${ }^{25-27}$ In our experimental conditions, variations in the degree of ischemia during carotid ligation and hypotension is likely the main factor 
responsible for the differences between the lesions found in SHRs and WKYs. Moreover, as BCAO alone is not enough to reduce $\mathrm{CBF}$ to the ischemic range in the rat, it is possible that the higher degree of forebrain ischemia observed in SHRs depended on hypotension and collateral blood supply. ${ }^{1}$

In conclusion, in the SHRs and WKYs analyzed at seven days after 20-min forebrain ischemia, two patterns of ischemic injury were observed. The first, found in WKYs, consisted of mild neuronal injury associated with astrocytic hypertrophy whereas in the second, found in SHRs, there were more numerous and larger zones of neuronal necrosis, associated with astrocytic hypertrophy and proliferation. The EEG recorded directly in the hippocampus of the SHRs correlated with the histopathological findings. Therefore, power spectra analysis of the hippocampal EEG could be a suitable neurophysiological in vivo test in the SHR model of global ischemia. It permits prognostic information by monitoring the effects of pharmacological treatments begun immediately after the onset of cerebral ischemia. The results of an EEG power spectra analysis obtained at $48 \mathrm{~h}$ might already be indicative of the efficacy of a pharmacological intervention.

\section{ACKNOWLEDGMents}

We thank Dr C.B. Gillies for English editing. This research was supported by University of Perugia and Sigma-Tau.

\section{REFERENCES}

1. Ginsberg MD, Busto R. Rodent models of cerebral ischemia. Stroke 1989; 20: 1627-1642.

2. Hunter AJ, Green AR, Cross AJ. Animal models of acute ischaemic stroke: can they predict clinically successful neuroprotective drugs? Trends Pharmacol Sci 1995; 16: 123-128.

3. Yanagihara T. Experimental Stroke in gerbils: correlation of clinical, pathological and electroencephalographic findings and protein syntesis. Stroke 1978; 9: 155-159.

4. Suzuki R, Yamaguchi T, Li CL, Klatza I. The effects of 5-minute ischemia in Mongolian gerbils: II.Changes of spontaneous neuronal activity in cerebral cortex and CA1 sector of Hippocampus. Acta Neuropathol 1983; 60: 217-222.

5. Araki H, Nojiri M, Kawashima K, Kimura M, Aihara H. Behavioral, electroencephalographic and histopathological studies on mongolian gerbils with occluded common carotid arteries. Physiol Behav 1986; 38: 89-94.

6. Gambelunghe $\mathrm{C}$, Mariucci G, Bruschelli $\mathrm{G}$, et al. Response variability to ischemic injury in the Mongolian gerbil: an electroencephalographic and behavioral study. Ital J Neurol Sci 1996; 17: 219-225.

7. Sainio K, Stenberg D, Keskimaki I, Muuronen A, Kaste M. Visual and spectral EEG analysis in the evaluation of outcome in patients with ischemic brain infarction. Electroenceph Clin Neurophysiol 1983; 56: 117-124.

8. Macdonell RA, Donnan GA, Bladin PF, Berkovic SF, Wriedt CH. The electroencephalogram and acute ischemic stroke. Distinguishing cortical from lacunar infarction. Arch Neurol 1988; 45: 520-524.

9. Murri L, Gori S, Massetani R, et al. Evaluation of acute ischemic stroke using quantitative EEG: a comparison with conventional EEG and CT SCAN. Neurophysiol Clin 1998; 28: 249-257.
10. Jordan KG. Continuous EEG monitoring in the neuroscience intensive care unit and emergency department. J Clin Neurophysiol 1999; 16: 14-39.

11. Petito CK, Morgello S, Felix JC, Lesser ML. The two patterns of reactive astrocytosis in postischemic rat brain. $\mathrm{J}$ Cereb Blood Flow Met 1990; 10: 850-859.

12. Zimmer C, Sampaolo S, Shanker Sharma H, Cervos-Navarro J. Alterated glial fibrillary acidic protein immunoreactivity in rat brain following chronic hypoxia. Neuroscience 1991; 40: 353361.

13. Kindy MS, Bhat AN, Bhat NR. Transient ischemia stimulates glial fibrillary acid protein and vimentin gene expression in the gerbil neocortex, striatum and hippocampus. Mol Brain Res 1992; 13: 199-206.

14. Janeczko K. Expression of GFAP and vimentin in astrocytes proliferating in response to injury in the mouse cerebral hemisphere. A combined autoradiographic and double immmunocytochemical study. Int J Dev Neurosci 1993; 11: 139147.

15. Stringer JL. Repeated seizures increase GFAP and Vimentin in hippocampus. Brain Res 1996; 717: 147-153.

16. Calvo JL, Carbonell AL, Boya J. Coexpression of glial fibrillary acidic protein and vimentin in reactive astrocytes following brain injury in rats. Brain Res 1991; 566: 333-336.

17. Schiffer D, Giordana MT, Cavalla P, Vigliani MC, Attanasio A. Immunohistochemistry of glial reaction after injury in the rat: double stainings and markers of cell proliferation. Int $\mathrm{J}$ Devl Neurosci 1993; 11: 269-280.

18. Chen H, Chopp M, Schultz L, Bodzin G, Garcia JH. Sequential neuronal and astrocytic changes after transient middle cerebral artery occlusion in the rat. J Neurol Sci 1993; 118: 109-116.

19. Ogata J, Fujishima M, Morotomi Y, Omae T. Cerebral infarction following bilateral carotid artery ligation in normotensive and spontaneously hypertensive rats: a pathological study. Stroke 1976; 7: 54-60.

20. Brint S, Jacewicz M, Kiessling M, Tanabe J, Pulsinelli W. Focal brain ischemia in the rat: methods for reproducible neocortical infarction using tandem occlusion of the distal middle cerebral and ipsilateral commmon carotid arteries. J Cereb Blood Flow Metab 1988; 8: 474-485.

21. Duverger D, MacKenzie ET. The quantification of cerebral infarction following focal ischemia in the rat: influence of strain, arterial pressure, blood glucose concentration and age. J Cereb Blood Flow Metab 1988; 8: 449-461.

22. Fujishima M, Tamaki K, Nakatomi Y, et al. Experimental cerebral ischemia in spontaneously hypertensive rats (SHR): importance of degree of hypertension. Stroke 1980; 11: 612-616.

23. Coyle P. Different susceptibilities to cerebral infarction in spontaneusly hypertensive (SHR) and normotensive SpragueDawley rats. Stroke 1986; 17: 520-525.

24. Kusuda K, Ibayashi S, Sadoshima S, Ishitsuka T, Fujishima M. Brain ischemia following bilateral carotid occlusion during development of hypertension in young spontaneously hypertensive rats: importance of morphologic changes of the arteries of the circle of Willis. Angiology 1996; 47: 455-465.

25. Rubattu S, Volpe M, Kreutz R, et al. Chromosomal mapping of quantitative trait loci contributing to stroke in a rat model of complex human disease. Nat Genet 1996; 13: 429-434.

26. Gratton JA, Sauter A, Rudin M, et al. Susceptibility to cerebral infarction in the stroke-prone spontaneously hypertensive rat is inherited as a dominant trait. Stroke 1998; 29: 690-694.

27. Rubattu S, Volpe M. Genetic basis of cerebrovascular accidents associated with hypertension. Cardiologia 1999; 44: 433-437. 